\title{
Impact of left ventricular function on clinical outcomes among patients with coronary artery disease
}

George CM Siontis, MD, PhD'; Mattia Branca, MSc${ }^{2}$; Patrick Serruys, MD, $\mathrm{PhD}^{3}$; Sigmund Silber, MD; Lorenz Räber, MD, PhD'; Thomas Pilgrim, MD'; Marco Valgimigli, MD, PhD; Dik Heg, PhD²; Stephan Windecker, MD'; Lukas Hunziker, MD1,"

\footnotetext{
1Department of Cardiology, University Hospital of Bern, Inselspital, 3010 Bern, Switzerland ${ }^{2}$ Clinical Trials Unit, University of Bern, Bern, Switzerland.

${ }^{3}$ Imperial College of Science, Technology and Medicine, London, United Kingdom.

${ }^{4}$ Department of Cardiology, Heart Centre at the Isar, Munich, Germany.
}

\section{*Corresponding author:}

Lukas Hunziker, MD

Director, Acute and Chronic Heart Failure

Department of Cardiology

Bern University Hospital, University of Bern, Inselspital

3010 Bern, Switzerland

Email: lukas.hunziker@insel.ch

http://www.insel.ch/kardio 


\section{ABSTRACT}

Aims: To investigate the clinical relevance of contemporary cutoffs of left ventricular ejection fraction (LVEF) including an intermediate phenotype with mid-range reduced ejection fraction (EF) among patients with coronary artery disease (CAD) undergoing percutaneous coronary intervention $(\mathrm{PCl})$.

Methods and Results: Patient-level data were summarized from five randomized clinical trials in which 6,198 patients underwent clinically indicated $\mathrm{PCl}$ in different clinical settings. We assessed all-cause mortality as primary endpoint at 5-year follow-up. According to the proposed LVEF cutoffs, 3,816 patients were included in the preserved LVEF group (LVEF $\geq 50 \%$ ), 1,793 in the mid-range reduced LVEF group (LVEF 40-49\%), and 589 patients in the reduced LVEF group (LVEF $<40 \%)$. Patients in the reduced LVEF group were at increased risk for the primary outcome of all-cause mortality compared with both, preserved and mid-range LVEF throughout 5 years of follow-up (adjusted HR $2.39(95 \% \mathrm{Cl} 1.75-3.28, \mathrm{p}<0.001)$ and $1.68(95 \% \mathrm{Cl} 1.34-2.10$, $\mathrm{p}<0.001)$, respectively). The risk of cardiac death and the composite endpoint of cardiac death, myocardial infarction, or stroke were higher for patients in the reduced LVEF group compared with the preserved and mid-range reduced LVEF groups, but also for the mid-range LVEF compared to preserved LVEF group (adjusted $p<0.05$ for all comparisons) throughout 5 years. Irrespective of clinical presentation at baseline (stable CAD or acute coronary syndrome), patients with reduced or mid-range LVEF were at increased risk of all-cause mortality and cardiac death up to 5 -years compared to the other group (adjusted $p<0.05$ for all comparisons).

Conclusion: Patients with reduced LVEF $<40 \%$ or mid-range LVEF $40-49 \%$ in the context of CAD undergoing clinically indicated $\mathrm{PCI}$ are at increased risk of all-cause mortality, cardiac death and the composite of cardiac death, stroke and myocardial infarction throughout 5 years of follow-up. The recently proposed LVEF cut-offs contribute to the differentiation and risk stratification of patients with ischemic heart disease. 
Keywords: heart failure, left ventricular ejection fraction, heart failure reduce ejection fraction, myocardial infarction, risk stratification. 
Abstract word count: 300 words

Manuscript word count: 4120 words

Number of Tables: 3

Number of Figures: 4 


\section{INTRODUCTION}

Left ventricular dysfunction due to coronary artery disease (CAD) remains a major cause of morbidity and mortality with considerable burden of disease worldwide. ${ }^{1}$ Patients with left ventricular dysfunction and symptoms of heart failure (HF) represent a clinical challenge because of the complex pathophysiological substrate and comorbidity interplay. ${ }^{2}$ Previous studies of patients with CAD and reduced left ventricular ejection fraction (LVEF) (LVEF $<40 \%$ ) have shown favourable results of coronary revascularization (either with percutaneous coronary intervention $(\mathrm{PCl})$ or coronary artery bypass grafting (CABG)) compared with a medical management alone. ${ }^{3,4}$ However, the most recent guidelines of the American College of Cardiology Foundation (ACCF)/AHA and European Society of Cardiology are not uniform with respect to the class and level of treatment recommendations for patients with $\mathrm{HF}$ and CAD suitable for revascularization. The European Society of Cardiology (ESC) guidelines recommend any intervention that would achieve complete revascularization (CABG or $\mathrm{PCl}$ ) for patients with $\mathrm{HF}$ and significant CAD in the presence of symptoms of angina and the presence of viable myocardium. ${ }^{5}$ The American College of Cardiology Foundation (ACCF)/AHA guidelines recommend $\mathrm{CABG}$ or $\mathrm{PCl}$ in patients with left main or multivessel disease in case of symptomatic patients without requiring evidence of ischemia. ${ }^{6}$ Recently, the ESC guidelines on acute and chronic HF suggested an additional intermediate phenotype in addition to the existing reduced LVEF of $<40 \%$ and preserved LVEF of $\geq 50 \%$ referred to as heart failure with mid-range ejection fraction (LVEF $40-49 \%$ ). ${ }^{7}$ Nevertheless, the chosen cutoff of $40 \%$ has been disputed as its prognostic relevance is under question and trials on neurohormonal antagonism have used different inclusion criteria. ${ }^{8}$

Against this background, we sought to investigate the impact of left ventricular systolic function by applying the recently proposed LVEF cutoffs ${ }^{7}$ in a large sample of patients with CAD undergoing $\mathrm{PCl}$ in the context of different clinical settings. 


\section{METHODS}

\section{Data sources, study population and interventions}

We summarized patient-level data from five randomized clinical trials (SIRTAX (NCT00297661) ${ }^{9}$, LEADERS (NCT00389220)10,11, RESOLUTE (NCT00617084)12, 13, COMFORTABLE (NCT00962416) ${ }^{14}$ and BIOSCIENCE (NCT01443104) ${ }^{15,16}$ ) with long-term follow-up conducted from 2004 to 2014 at European institutions. Detailed individual study design and trial results are available in the individual publications of the trials (Supplementary Table 1). ${ }^{9-16}$ Briefly, all studies included patients with CAD referred for clinically indicated $\mathrm{PCI}$ in different clinical setting (corresponding to stable CAD, non-ST-elevation acute coronary syndrome (NSTE-ACS), or STelevation myocardial infarction (STEMI)) that were amendable to coronary stent implantation. In the individual trials, patients were randomly assigned to one of two different stent platforms (either bare-metal (BMS) or drug-eluting stents (DES)) following pre-specified protocols

(Supplementary Table 1). For the purpose of this study, we included all patients with available information on left ventricular (LV) function. LV function was determined at baseline prior to the index intervention by left ventricular angiography or transthoracic echocardiography as reported in the case record form.

All studies complied with the Declaration of Helsinki and were approved by the ethical review board in each institution. All patients in the individual trials had provided written informed consent to be prospectively followed. The case report forms were verified or checked for plausibility by an independent monitoring provider in the individual studies. The databases used in this study only contained anonymous patient records.

\section{Outcomes definitions and follow-up}

Assessed outcomes across the trials were adjudicated with similar standardized definitions as has been previously reported. ${ }^{17}$ The primary outcome in our analysis was all-cause mortality. Secondary outcomes included cardiac death, myocardial infarction (MI), composite of cardiac 
death, MI or stroke, Q-wave MI, non Q-Wave MI, stroke, any target lesion revascularization (TLR), any target-vessel revascularization (TVR), and any revascularization up to 5-years followup. Follow-up in individual trials was prospectively performed at 30-days, 1-year and annually thereafter throughout 5-years. For this analysis, 5-year follow-up data were available for all trials. Individual patients were censored at the valid contact in case of lost-to-follow-up or withdrawal of the consent.

\section{Statistical analysis}

We stratified the study population according to the recently proposed LVEF cutoffs ${ }^{7}$ into three groups of $\geq 50 \%, 40-49 \%$, and $<40 \%$. Descriptive statistics of baseline continuous variables were presented as mean \pm standard deviation (SD) and compared with independent samples Student t-test; categorical variables were expressed as frequencies and percentages and compared with Fisher's exact or chi-squared test. We evaluated different cut-offs in our dataset comparing them with the Harrel's $\mathrm{C}$ index. Clinical outcomes at 5 years were expressed as counts with percentage for the overall population, and stratified according to clinical presentation (stable CAD or ACS). We performed additional analyses by breaking down the ACS group into two subgroups (NSTE-ACS and STEMI). We performed a survival parametric model with Weibull distribution, $\mathrm{PH}$ model, for the overall population and the stratified population to calculate hazard ratios (HRs) with accompanied 95\% confidence intervals (Cls). We considered the different trials as random effect and we derived adjusted HRs performing maximum likelihood estimation from multivariable survival parametric models for the overall population and stratified groups for all the endpoints. We obtained adjusted HRs by considering baseline characteristics, excluding PCI related information and those variables with $\geq 30 \%$ of missing values or those variables not available in a particular study. Adjustment was performed for age, gender, body-mass index, diabetes mellitus, insulin-treatment, diabetes diet or oral treatment at baseline, hypertension, current smoker, family history of coronary artery disease, previous myocardial infarction, 
previous percutaneous coronary interventions, previous coronary artery bypass-graft, acute coronary syndrome group, renal failure, and glycoprotein llb/llla antagonist use at procedure. We imputed the missing values by using multiple imputation to obtain the final model. The Kaplan-Meier curves, were obtained for the endpoints of all-cause mortality, cardiac death and the composite of cardiac death, $\mathrm{MI}$ and stroke; and stratified according to the specified LVEF groups. We considered a landmark analysis using a time point at 30-days, with HRs computed separately for events up to 30-days and from 30-days to 5-years. Finally, we used fractional polynomial to analyze the LVEF versus all-cause mortality. In the latter case, fractional polynomials with one degree were used to obtain the estimation of the effect of LVEF versus log hazard of all-cause mortality and the values were centered at the value of 50 . HRs are considered statistically significant at $5 \%$ level. All statistical analyses were performed with Stata version 15.0 (StataCorp. 2017, College Station, TX). 


\section{RESULTS}

\section{Study population and baseline clinical characteristics}

A total of 8,287 patients were enrolled into 5 trials of whom 6,198 patients fulfilled the eligibility criteria and were included in this pooled analysis (Figure 1, Table 1). The Harrel's C comparison in the study population confirms that for an unadjusted model the best cut-offs of LVEF for the mid-range reduced LVEF group are those proposed by the recent ESC guidelines (LVEF 40$49 \%$ ), while for the adjusted model, the best lower cut-off value would be a LVEF of $35 \%$

(Supplementary Table 2). According to the proposed LVEF cutoffs 7 , 3,816 patients were included in the preserved LVEF ( $\geq 50 \%$ ) group, 1,793 mid-range reduced LVEF (40-49\%) group, and 589 in the reduced LVEF (<40\%) group. Table 1 and Supplementary Tables $\mathbf{3}$ and $\mathbf{4}$ summarize baseline demographics and procedural characteristic of the study population. Baseline characteristics differed considerably across the three groups with patients in $\mathrm{LVEF}<40 \%$ group featuring a more severe cardiovascular-risk profile and a higher proportion of advanced Killip Class (III or IV) at presentation (Table 1). In our study sample, $60 \%$ of patients presented with acute coronary syndromes (ACS) (29\% NSTE-ACS and 31\% STEMI). Multivessel revascularization was performed in $30 \%$ of the overall population and was equally represented across the three groups of LVEF.

\section{Clinical outcomes}

Clinical outcomes throughout 5 years are summarized in Supplementary Table 4 for the overall study population stratified according to LVEF group and clinical presentation. In crude analyses, patients with reduced LVEF $<40 \%$ experienced higher rates of all-cause mortality compared with both, the preserved and mid-range reduced LVEF group ( $24 \%$ versus $8 \%$ and $13 \%$, respectively) with unadjusted hazard ratios of $1.56(95 \% \mathrm{Cl}, 1.36$ to 1.80$)$ for mid-range vs. preserved LVEF group, $3.32(95 \% \mathrm{Cl}, 2.81$ to 3.93$)$ for reduced vs. preserved LVEF group, and $2.13(95 \% \mathrm{Cl}, 1.78$ to 2.54$)$ for reduced vs. mid-range reduced LVEF group (Supplementary Table 5) at 5 years of follow-up. Following multivariable adjustment, patients in the reduced 
LVEF $<40 \%$ group remained at increased risk for all-cause mortality compared with preserved LVEF $\geq 50 \%$ (adjusted HR 2.39 (95\% $\mathrm{Cl} 1.75$ to 3.28 ), p<0.001) or mid-range LVEF $40-49 \%$ (adjusted HR $1.68(95 \% \mathrm{Cl} 1.34$ to 2.10), $\mathrm{p}<0.001)$ throughout 5 years of follow-up (Table 2 and Figure 2). The risk of cardiac death and the composite endpoint of cardiac death, myocardial infarction, or stroke remained higher for patients in the reduced LVEF group compared with either the preserved or mid-range LVEF group (adjusted $p<0.05$ for all comparisons). In a landmark analysis at 30 days of follow-up, the risk of all-cause mortality was higher for the reduced LVEF group compared with the preserved LVEF group (adjusted HR of $8.82(95 \% \mathrm{Cl}$, 2.02 to 38.60$), p<0.001)$. The mid-range LVEF group remained at increased risk of all-cause mortality and cardiac death compared to the preserved LVEF group during the first 30 days and continued to be at increased risk up to 5 years (adjusted $p<0.05$ for all comparisons) (Table 2 and Figure 2). The trend of risk over time for cardiac death was consistent with that for all-cause mortality with a higher risk for the reduced LVEF group compared with either the preserved LVEF (adjusted HR $3.07(95 \% \mathrm{Cl}, 2.14$ to 4.42$), \mathrm{p}<0.001)$ or the mid-range LVEF group (adjusted HR $1.74(95 \% \mathrm{Cl}, 1.22$ to 2.50$), \mathrm{p}=0.002)$ throughout five years of follow-up.

\section{Outcomes according to initial clinical setting}

The clinical indication for $\mathrm{PCl}$ at baseline was ACS in $60 \%$ of the participants (either NSTE-ACS $(29 \%)$ or STEMI $(31 \%))$, while $40 \%$ of the participants presented with stable CAD (Table 1). Detailed outcomes stratified according to initial clinical presentation and LVEF group at baseline are provided in Supplementary Table 4. The unadjusted analyses indicated an increased risk of all-cause mortality, cardiac death and the composite endpoint of cardiac death, MI, or stroke ( $p<0.05$ for all comparisons of subgroups) across the entire spectrum of clinical presentations for reduced over preserved and mid-range LVEF group, and also for mid-range over preserved LVEF group (Supplementary Table 6 and 7). After adjusting for differences in baseline characteristics, patients with reduced LVEF ( $<40 \%)$ presenting with either stable CAD or ACS 
remained at increased risk of all-cause mortality and cardiac death compared to both preserved and mid-range LVEF group throughout 5 years of follow-up ( $p<0.05$ for all comparisons) (Table 3, Figure 3). Patients initially presenting with either stable CAD or ACS and reduced LVEF $<40 \%$ were at increased risk of cardiac death compared with preserved LVEF $\geq 50 \%$ (adjusted HR of $2.64(95 \% \mathrm{Cl} 1.71$ to $4.06, \mathrm{p}<0.001)$ and $3.48(95 \% \mathrm{Cl} 2.27$ to $5.33, \mathrm{p}<0.001)$ respectively $)$ (Supplementary Table 8 and Supplementary Figure). Patients with mid-range LVEF 40-49\% were well differentiated and at higher risk of all-cause mortality and cardiac death compared to preserved LVEF $\geq 50 \%$ in both clinical settings (adjusted $p<0.001$ for all comparisons) (Table 3). In a spline analysis using fractional polynomial stratified according to clinical setting at baseline (Figure 4) patients with lower LVEF had a higher hazard of all-cause mortality, particularly in the group of ACS patients. 


\section{DISCUSSION}

The present study provides comprehensive evidence applying the recently proposed LVEF cutoffs to a large group of patients with CAD undergoing clinically indicated $\mathrm{PCl}$ followed throughout 5 years of follow-up with adjudicated clinical endpoint assessment in the context of carefully conducted randomized clinical trials. The salient findings of our analysis can be summarized as follows:

- Patients with reduced LVEF $<40 \%$ are at increased risk of all-cause mortality and cardiac death compared with those with preserved and mid-range LVEF throughout 5 years.

- The difference in mortality emerges early (within 30 days) and continues to increase over time (throughout 5 years).

- Patients with mid-range LVEF $40-49 \%$ are well differentiated and at increased risk of allcause mortality and cardiac death compared with those with preserved LVEF $\geq 50 \%$ throughout 5 years.

- The risk of all-cause mortality and cardiac death is higher for patients with reduced $\mathrm{LVEF}<40 \%$ irrespective of clinical indication (stable CAD or ACS) compared to preserved and mid-range reduced LVEF.

The prognostic relevance of LVEF to appropriately risk stratify patients over the whole spectrum of LV function and heart failure phenotype remains subject of debate. In a post-hoc analysis of the CHARM trial, LVEF was shown to function as a good predictor of cardiovascular outcomes only for patients with heart failure and LVEF $<45 \% .{ }^{18}$ The findings of the Meta-analysis Global Group in Chronic Heart Failure (MAGGIC) indicated no significant increase in the risk of all-cause mortality or cardiovascular death in patients with either LVEF $50-59 \%$ or $40-49 \%$ compared with patients with LVEF of $60 \%$ or above, whereas the hazard for death increased steadily below a LVEF of $40 \% .{ }^{19}$ However, in our study sample, the proposed LVEF cut-offs did appropriately risk discriminate the patients among the spectrum of mid-range and preserved LV 
function. These findings are in concordance with recently published large scale meta-analysis, highlighting the distinct prognostic role of mid-range LVEF group. ${ }^{20,21}$

We were able to demonstrate that patients with impaired LVEF at baseline irrespective of initial clinical presentation (stable CAD or ACS) remain at increased risk of death compared to patients with either preserved or mid-range impaired LV function throughout 5 years. Most studies, of heart failure with depressed systolic function, report only a single LVEF measurement, generally obtained at baseline. Notwithstanding, the heart failure syndrome includes multiple diverging patient-specific phenotypes, resulting in a wide spectrum of LVEF trajectories over time depending on underlying aetiology, duration, and gender. ${ }^{22,23}$ In a large prospective cohort of patients with heart failure and echocardiographic assessment of LV function at several time points (mean 3.6 \pm 1.7 ) over 15 years, LV function in patients with ischemic heart failure improved to a lesser degree compared with patients with non-ischemic heart failure within the first year of initial assessment followed by a relative plateau thereafter. Of note a decline in LVEF as compared to the preceding period was associated with higher mortality. ${ }^{22}$ The findings of our study corroborate those of the HORIZONS-AMI trial, where severe LV dysfunction (LVEF $<40 \%$ ) determined during the acute phase of STEMI patients undergoing primary $\mathrm{PCl}$ was a powerful independent predictor of adverse clinical outcomes during 3 years follow-up. ${ }^{24}$ Similarly, a retrospective analysis of the CADILLAC trial reported an increased risk of all-cause mortality at 1 year of follow-up among STEMI patients with baseline LVEF $<40 \%$ as compared to those with baseline LVEF $>40 \% .{ }^{25}$ The present study extends these findings suggesting that baseline LV dysfunction impacts on survival up to 5 years. However, a recently published meta-analysis highlighted the prognostic importance and favourable outcomes of heart failure patients with improved ejection fraction under optimal medical therapy, compared to those with persistently reduced ejection fraction. ${ }^{26}$ The role of ejection fraction improvement and appropriate identification of patients at higher risk should be evaluated in dedicated prospectively designed studies. 
Nevertheless, no specific heart failure treatment has been shown to improve prognosis among patients with preserved or mid-range reduced LVEF, and the management is mainly directed to the underlying disease entity (i.e. CAD in the present cohort), symptom relief and treatment of comorbidities. The lack of benefit of established medical treatment for patients with mid-range reduced or preserved LVEF can be partially explained by the heterogeneous phenotypes of patients, the absence of dedicated trials to investigate therapeutic strategies, and

the lack of established surrogate end points for these group of patients. ${ }^{27}$ At 5 years of follow-up, the patients with reduced LVEF remained at increased risk for all-cause mortality, cardiac death and the composite of cardiac death, stroke and myocardial infarction compared with both preserved and mid-range LVEF group in the present study. Previous studies have evaluated the prognostic impact of non-invasive diagnostic tests (e.g. cardiopulmonary exercise testing), invasive measurements (e.g. wedge pressure), and biomarkers across the entire spectrum of heart failure patients. ${ }^{28-30}$ However, it remains unclear whether such tools result in modification of therapeutic strategies and cost-effective improvement in patient outcomes.

Consistent with a previous study ${ }^{31}$, we found that a lower cut-off of LVEF $35 \%$ discriminates more precisely those patients with more severe systolic dysfunction and impaired prognosis, than the guideline proposed cut-off of $<40 \%$. However, in our study a small proportion of patients ( $8 \%$ of the group of LVEF $<40 \%$, corresponding to $0.8 \%$ of the whole study cohort with LVEF between 35\%-40\%) would influence the prognostic significance of the $40 \%$ cut-off, which possibly explains the slightly suboptimal discriminatory ability. Prospective large-scale studies should evaluate the clinical relevance of such differences in discriminatory performance.

\section{Limitations}

Several limitations should be acknowledged in the present study. First, this is a non-prespecified retrospective analysis of prospectively ascertained clinical data and therefore exploratory in nature. However, we analyzed data of a carefully documented series of patients that had been 
fully characterized in terms of baseline characteristics in the framework of RCTs and correlated LVEF in the context of different clinical settings with fully adjudicated long-term clinical outcomes up to 5-years follow-up. Second, values for LVEF are continuously distributed but measurement precision is known to be imperfect and differences up to $10 \%$ in individual patients may be attributed to measurement errors. ${ }^{32}$ Third, LVEF was available only at baseline and changes in LV function at follow-up were not ascertained; therefore we were unable to consider this parameter and its impact on long-term analysis in the present study. Forth, we were unable to correlate clinical heart failure status with objective parameters of left ventricular function. Finally, in any individual trial, there is always concerns about whether the study populations enrolled reflect the patients encountered in clinical practice due to selection criteria, and in toward to this aspect this analysis is not different. However, our dataset represents the vast majority of patients enrolled in RCTs PCI trials.

\section{Conclusions}

Patients with reduced LVEF $<40 \%$ or mid-range LVEF $40-49 \%$ in the context of CAD undergoing clinically indicated PCl are at increased risk of all-cause mortality, cardiac death and the composite of cardiac death, stroke and myocardial infarction throughout 5 years of follow-up. The recently proposed LVEF cut-offs contribute to the differentiation and risk stratification of patients with ischemic heart disease. 


\section{Funding}

No specific funding was obtained for this study.

\section{Acknowledgements}

None.

\section{Contributions}

GCMS, MB, DH, SW, and LH conceived and designed the study. MB and DH performed the statistical analyses. All authors interpreted the results. GCMS, SW, and LH drafted the first draft of the manuscript. All authors gave final approval and agreed to be accountable for all aspects of the work ensuring integrity and accuracy. All authors had full access to all of the data. $\mathrm{LH}$ is the guarantor.

\section{Conflicts of interest}

MB and DH are affiliated with CTU Bern, University of Bern, which has a staff policy of not accepting honoraria or consultancy fees. However, CTU Bern is involved in design, conduct, or analysis of clinical studies funded by not-for-profit and for-profit organizations. In particular, pharmaceutical and medical device companies provide direct funding to some of these studies. For an up-to-date list of CTU Bern's conflicts of interest see http://www.ctu.unibe.ch/research/declaration of interest/index eng.html. PWS reports consultancy fees from Abbott, Biosensors, Medtronic, Micell, Qualimed, Sinomedical Sciences, St. Jude Medical, Stentys, Svelte Medical Systems, Philips/Volcano, Xeltis, Stentlt and HeartFlow. TP has received research grants to the institution from Biotronik, Boston Scientific, and Edwards Lifesciences; and speaker fees from Biotronik and Boston Scientific. SW reports research grants to the institution from Amgen, Abbott, Biotronik, Boston Scientific, Medtronic, Edwards, St Jude and Terumo. The other authors have nothing to disclose relevant to this study. 


\section{FIGURES}

FIGURE 1: Flowchart of patients' selection process and group distribution according to LVEF in study population.

Abbreviations: RCTs, randomized controlled trials; LVEF, left ventricular ejection fraction.

FIGURE 2: Time-to-first event curves for patients across the three groups with preserved $(\geq 50 \%)$, mid-range $(40-49 \%)$ and reduced $(<40 \%)$ LVEF.

Panel A and B: All-cause mortality; Panel C and D: Composite outcome of cardiac death, MI, and stroke; Panel E and F: Cardiac death. Estimates are shown as adjusted hazard ratios (HRs) with accompanied $95 \%$ confidence intervals (Cls). A landmark analysis at time-point of 30 days is shown in Panels $B, D$, and $F$.

Abbreviations: Ml, myocardial infarction.

FIGURE 3: Time-to-first event curves for patients across the three groups with preserved ( $\geq 50 \%)$, mid-range $(40-49 \%)$ and reduced ( $<40 \%)$ LVEF stratified according to clinical presentation.

Panels A, B, and C: for the primary outcome of all-cause mortality; Panels D, E, and F: for the composite endpoint of cardiac death, myocardial infarction, or stroke; Panels $\mathrm{G}, \mathrm{H}$, and I: for the outcome of cardiac death. Estimates are shown as adjusted hazard ratios (HRs) with accompanied $95 \%$ confidence intervals (Cls).

Abbreviations: MI, myocardial infarction; CAD, coronary artery disease; ACS, acute coronary syndrome. 
FIGURE 4: Fractional polynomial stratified according to clinical setting at baseline for allcause mortality.

Panel A: Overall; Panel B: Stable CAD; Panel C: ACS.

Abbreviations: HR, hazard ratio; LVEF, left ventricular ejection fraction; CAD, coronary artery disease; ACS, acute coronary syndrome. 


\section{TABLES}

\section{TABLE 1: Baseline clinical characteristics.}

Data are shown as $n$, count (\%) and mean \pm SD as appropriate.

Abbreviations: LVEF, left ventricular ejection fraction; BMI, body mass index; GFR, glomerular filtration rate; CAD, coronary artery disease; $\mathrm{MI}$, myocardial infarction; $\mathrm{PCI}$, percutaneous coronary intervention; CABG, coronary artery bypass grafting; NSTE-ACS, non-ST elevation acute coronary syndrome; STEMI, ST elevation myocardial infarction.

TABLE 2: Clinical outcomes at 5 years of follow-up across the three groups of preserved ( $\geq 50 \%)$, mid-range (40-49\%) and reduced (<40\%) LVEF.

Data shown are adjusted hazard rations (HR) with 95\% confidence intervals (Cl). Adjustment was performed for age, gender, body-mass index, diabetes mellitus, insulin-treatment, diabetes

diet or oral treatment at baseline, hypertension, current smoker, family history of coronary artery disease, previous myocardial infarction, previous percutaneous coronary interventions, previous coronary artery bypass-graft, acute coronary syndrome group, renal failure, glycoprotein Ilb/IIla antagonist use at procedure.

Abbreviations: LVEF, left ventricular ejection fraction; HR, hazard ratio; Cl, confidence interval; MI, myocardial infarction; TLR, target lesion revascularisation; TVR, target vessel revascularisation.

TABLE 3: Clinical outcomes at 5 years of follow-up across the three groups of preserved ( $\geq 50 \%)$, mid-range (40-49\%) and reduced (<40\%) LVEF according to clinical presentation. Data shown are adjusted hazard rations $(\mathrm{HR})$ with $95 \%$ confidence intervals $(\mathrm{Cl})$. Adjustment as reported in Table 2. 
Abbreviations: LVEF, left ventricular ejection fraction; HR, hazard ratio; $\mathrm{Cl}$, confidence interval; CAD, coronary artery disease; ACS, acute coronary syndrome; MI, myocardial infarction; TLR, target lesion revascularisation; TVR, target vessel revascularisation. 


\section{REFERENCES}

1. Benjamin EJ, Virani SS, Callaway CW, Chamberlain AM, Chang AR, Cheng S, Chiuve SE, Cushman M, Delling FN, Deo R, de Ferranti SD, Ferguson JF, Fornage M, Gillespie C, Isasi CR, Jimenez MC, Jordan LC, Judd SE, Lackland D, Lichtman JH, Lisabeth L, Liu S, Longenecker CT, Lutsey PL, Mackey JS, Matchar DB, Matsushita K, Mussolino ME, Nasir K, O'Flaherty M, Palaniappan LP, Pandey A, Pandey DK, Reeves MJ, Ritchey MD, Rodriguez CJ, Roth GA, Rosamond WD, Sampson UKA, Satou GM, Shah SH, Spartano NL, Tirschwell DL, Tsao CW, Voeks JH, Willey JZ, Wilkins JT, Wu JH, Alger HM, Wong SS, Muntner P, American Heart Association Council on E, Prevention Statistics C, Stroke Statistics S. Heart disease and stroke statistics-2018 update: A report from the american heart association. Circulation. 2018;137:e67-e492

2. Triposkiadis F, Giamouzis G, Parissis J, Starling RC, Boudoulas H, Skoularigis J, Butler J, Filippatos G. Reframing the association and significance of co-morbidities in heart failure. Eur J Heart Fail. 2016;18:744-758

3. Bangalore S, Guo Y, Samadashvili Z, Blecker S, Xu J, Hannan EL. Everolimus-eluting stents or bypass surgery for multivessel coronary disease. $N$ Engl J Med. 2015;372:1213-1222

4. Marui A, Kimura T, Nishiwaki N, Mitsudo K, Komiya T, Hanyu M, Shiomi H, Tanaka S, Sakata R, Investigators CR-KPCRC-. Comparison of five-year outcomes of coronary artery bypass grafting versus percutaneous coronary intervention in patients with left ventricular ejection fractions $</=50 \%$ versus $>50 \%$ (from the credo-kyoto pci/cabg registry cohort-2). Am J Cardiol. 2014;114:988-996

5. Neumann FJ, Sousa-Uva M, Ahlsson A, Alfonso F, Banning AP, Benedetto U, Byrne RA, Collet JP, Falk V, Head SJ, Juni P, Kastrati A, Koller A, Kristensen SD, Niebauer J, Richter DJ, Seferovic PM, Sibbing D, Stefanini GG, Windecker S, Yadav R, Zembala MO, Group ESCSD. 2018 esc/eacts guidelines on myocardial revascularization. Eur Heart J. 2018

6. Fihn SD, Blankenship JC, Alexander KP, Bittl JA, Byrne JG, Fletcher BJ, Fonarow GC, Lange RA, Levine GN, Maddox TM, Naidu SS, Ohman EM, Smith PK. 2014 acc/aha/aats/pcna/scai/sts focused update of the guideline for the diagnosis and management of patients with stable ischemic heart disease: A report of the american college of cardiology/american heart association task force on practice guidelines, and the american association for thoracic surgery, preventive cardiovascular nurses association, society for cardiovascular angiography and interventions, and society of thoracic surgeons. J Am Coll Cardiol. 2014;64:1929-1949

7. Ponikowski P, Voors AA, Anker SD, Bueno H, Cleland JGF, Coats AJS, Falk V, Gonzalez-Juanatey JR, Harjola VP, Jankowska EA, Jessup M, Linde C, Nihoyannopoulos P, Parissis JT, Pieske B, Riley JP, Rosano GMC, Ruilope LM, Ruschitzka F, Rutten FH, van der Meer P, Group ESCSD. 2016 esc guidelines for the diagnosis and treatment of acute and chronic heart failure: The task force for the diagnosis and treatment of acute and chronic heart failure of the european society of cardiology (esc)developed with the special contribution of the heart failure association (hfa) of the esc. Eur Heart J. 2016;37:2129-2200

8. Packer M. Heart failure with a mid-range ejection fraction: A disorder that a psychiatrist would love. JACC Heart Fail. 2017;5:805-807 
9. Windecker S, Remondino A, Eberli FR, Juni P, Raber L, Wenaweser P, Togni M, Billinger M, Tuller D, Seiler C, Roffi M, Corti R, Sutsch G, Maier W, Luscher T, Hess OM, Egger M, Meier B. Sirolimus-eluting and paclitaxel-eluting stents for coronary revascularization. N Engl J Med. 2005;353:653-662

10. Windecker S, Serruys PW, Wandel S, Buszman P, Trznadel S, Linke A, Lenk K, Ischinger T, Klauss V, Eberli F, Corti R, Wijns W, Morice MC, di Mario C, Davies S, van Geuns RJ, Eerdmans P, van Es GA, Meier B, Juni P. Biolimus-eluting stent with biodegradable polymer versus sirolimus-eluting stent with durable polymer for coronary revascularisation (leaders): A randomised non-inferiority trial. Lancet. 2008;372:11631173

11. Serruys PW, Farooq V, Kalesan B, de Vries $T$, Buszman $P$, Linke A, Ischinger $T$, Klauss V, Eberli F, Wijns W, Morice MC, Di Mario C, Corti R, Antoni D, Sohn HY, Eerdmans P, Rademaker-Havinga T, van Es GA, Meier B, Juni P, Windecker S. Improved safety and reduction in stent thrombosis associated with biodegradable polymer-based biolimuseluting stents versus durable polymer-based sirolimus-eluting stents in patients with coronary artery disease: Final 5-year report of the leaders (limus eluted from a durable versus erodable stent coating) randomized, noninferiority trial. JACC Cardiovasc Interv. 2013;6:777-789

12. Silber S, Windecker S, Vranckx P, Serruys PW, investigators RAC. Unrestricted randomised use of two new generation drug-eluting coronary stents: 2-year patientrelated versus stent-related outcomes from the resolute all comers trial. Lancet. $2011 ; 377: 1241-1247$

13. lqbal J, Serruys PW, Silber S, Kelbaek H, Richardt G, Morel MA, Negoita M, Buszman PE, Windecker S. Comparison of zotarolimus- and everolimus-eluting coronary stents: Final 5-year report of the resolute all-comers trial. Circ Cardiovasc Interv. 2015;8:e002230

14. Raber L, Kelbaek H, Ostojic M, Baumbach A, Heg D, Tuller D, von Birgelen C, Roffi M, Moschovitis A, Khattab AA, Wenaweser P, Bonvini R, Pedrazzini G, Kornowski R, Weber K, Trelle S, Luscher TF, Taniwaki M, Matter CM, Meier B, Juni P, Windecker S, Investigators CAT. Effect of biolimus-eluting stents with biodegradable polymer vs baremetal stents on cardiovascular events among patients with acute myocardial infarction: The comfortable ami randomized trial. JAMA. 2012;308:777-787

15. Pilgrim T, Heg D, Roffi M, Tuller D, Muller O, Vuilliomenet A, Cook S, Weilenmann D, Kaiser C, Jamshidi P, Fahrni T, Moschovitis A, Noble S, Eberli FR, Wenaweser P, Juni $P$, Windecker $S$. Ultrathin strut biodegradable polymer sirolimus-eluting stent versus durable polymer everolimus-eluting stent for percutaneous coronary revascularisation (bioscience): A randomised, single-blind, non-inferiority trial. Lancet. 2014;384:21112122

16. Pilgrim T, Piccolo R, Heg D, Roffi M, Tuller D, Muller O, Moarof I, Siontis GCM, Cook S, Weilenmann D, Kaiser C, Cuculi F, Hunziker L, Eberli FR, Juni P, Windecker S. Ultrathinstrut, biodegradable-polymer, sirolimus-eluting stents versus thin-strut, durable-polymer, everolimus-eluting stents for percutaneous coronary revascularisation: 5-year outcomes of the bioscience randomised trial. Lancet. 2018;392:737-746

17. Cutlip DE, Windecker S, Mehran R, Boam A, Cohen DJ, van Es GA, Steg PG, Morel MA, Mauri L, Vranckx P, McFadden E, Lansky A, Hamon M, Krucoff MW, Serruys PW, Academic Research C. Clinical end points in coronary stent trials: A case for standardized definitions. Circulation. 2007;115:2344-2351 
18. Solomon SD, Anavekar N, Skali H, McMurray JJ, Swedberg K, Yusuf S, Granger CB, Michelson EL, Wang D, Pocock S, Pfeffer MA, Candesartan in Heart Failure Reduction in Mortality I. Influence of ejection fraction on cardiovascular outcomes in a broad spectrum of heart failure patients. Circulation. 2005;112:3738-3744

19. Meta-analysis Global Group in Chronic Heart F. The survival of patients with heart failure with preserved or reduced left ventricular ejection fraction: An individual patient data meta-analysis. Eur Heart J. 2012;33:1750-1757

20. Altaie $S$, Khalife $W$. The prognosis of mid-range ejection fraction heart failure: $A$ systematic review and meta-analysis. ESC Heart Fail. 2018

21. Lauritsen J, Gustafsson F, Abdulla J. Characteristics and long-term prognosis of patients with heart failure and mid-range ejection fraction compared with reduced and preserved ejection fraction: A systematic review and meta-analysis. ESC Heart Fail. 2018;5:685694

22. Lupon J, Gavidia-Bovadilla G, Ferrer E, de Antonio M, Perera-Lluna A, Lopez-Ayerbe J, Domingo M, Nunez J, Zamora E, Moliner P, Diaz-Ruata P, Santesmases J, Bayes-Genis A. Dynamic trajectories of left ventricular ejection fraction in heart failure. J Am Coll Cardiol. 2018;72:591-601

23. Katritsis DG, Siontis KC, Bigger JT, Kadish AH, Steinman R, Zareba W, Siontis GC, Bardy $\mathrm{GH}$, loannidis JP. Effect of left ventricular ejection fraction and qrs duration on the survival benefit of implantable cardioverter-defibrillators: Meta-analysis of primary prevention trials. Heart Rhythm. 2013;10:200-206

24. Daneault B, Genereux P, Kirtane AJ, Witzenbichler B, Guagliumi G, Paradis JM, Fahy MP, Mehran R, Stone GW. Comparison of three-year outcomes after primary percutaneous coronary intervention in patients with left ventricular ejection fraction $<40 \%$ versus $>/=40 \%$ (from the horizons-ami trial). Am J Cardiol. 2013;111:12-20

25. Halkin A, Stone GW, Dixon SR, Grines CL, Tcheng JE, Cox DA, Garcia E, Brodie B, Stuckey TD, Mehran R, Lansky AJ. Impact and determinants of left ventricular function in patients undergoing primary percutaneous coronary intervention in acute myocardial infarction. Am J Cardiol. 2005;96:325-331

26. Jorgensen ME, Andersson C, Vasan RS, Kober L, Abdulla J. Characteristics and prognosis of heart failure with improved compared with persistently reduced ejection fraction: A systematic review and meta-analyses. Eur J Prev Cardiol. 2018;25:366-376

27. Senni M, Paulus WJ, Gavazzi A, Fraser AG, Diez J, Solomon SD, Smiseth OA, Guazzi M, Lam CS, Maggioni AP, Tschope C, Metra M, Hummel SL, Edelmann F, Ambrosio G, Stewart Coats AJ, Filippatos GS, Gheorghiade M, Anker SD, Levy D, Pfeffer MA, Stough WG, Pieske BM. New strategies for heart failure with preserved ejection fraction: The importance of targeted therapies for heart failure phenotypes. Eur Heart J. 2014;35:27972815

28. Chow SL, Maisel AS, Anand I, Bozkurt B, de Boer RA, Felker GM, Fonarow GC, Greenberg B, Januzzi JL, Jr., Kiernan MS, Liu PP, Wang TJ, Yancy CW, Zile MR, American Heart Association Clinical Pharmacology Committee of the Council on Clinical $\mathrm{C}$, Council on Basic Cardiovascular S, Council on Cardiovascular Disease in the $\mathrm{Y}$, Council on C, Stroke N, Council on Cardiopulmonary CCP, Resuscitation, Council on E, Prevention, Council on Functional G, Translational B, Council on Quality of C, Outcomes R. Role of biomarkers for the prevention, assessment, and management of heart failure: A scientific statement from the american heart association. Circulation. 2017;135:e1054e1091 
29. Damy T, Goode KM, Kallvikbacka-Bennett A, Lewinter C, Hobkirk J, Nikitin NP, DuboisRande JL, Hittinger L, Clark AL, Cleland JG. Determinants and prognostic value of pulmonary arterial pressure in patients with chronic heart failure. Eur Heart $J$. 2010;31:2280-2290

30. Sato T, Yoshihisa A, Kanno Y, Suzuki S, Yamaki T, Sugimoto K, Kunii H, Nakazato K, Suzuki H, Saitoh SI, Ishida T, Takeishi Y. Cardiopulmonary exercise testing as prognostic indicators: Comparisons among heart failure patients with reduced, mid-range and preserved ejection fraction. Eur J Prev Cardiol. 2017;24:1979-1987

31. Aimo A, Januzzi JL, Jr., Vergaro G, Petersen C, Pasanisi EM, Molinaro S, Passino C, Emdin M. Left ventricular ejection fraction for risk stratification in chronic systolic heart failure. Int J Cardiol. 2018;273:136-140

32. Picard MH, Popp RL, Weyman AE. Assessment of left ventricular function by echocardiography: A technique in evolution. J Am Soc Echocardiogr. 2008;21:14-21 
2089 patients

without LVEF

measurement

\section{LVEF $\geq 50 \%$} 3816 patients

\section{LVEF $40-49 \%$ \\ 1793 patients}

LVEF $<40 \%$ 589 patients
3816 patients with clinical primary endpoint available up to 5-years 3502 alive 314 died
1793 patients with clinical primary endpoint available up to 5-years 1569 alive 224 died
589 patients with clinical primary endpoint available up to 5-years 445 alive 144 died
1793 patients analysed

$1515 \geq 1750$ days follow-up $278<1750$ days follow-up
589 patients analysed

$425 \geq 1750$ days follow-up $164<1750$ days follow-up 

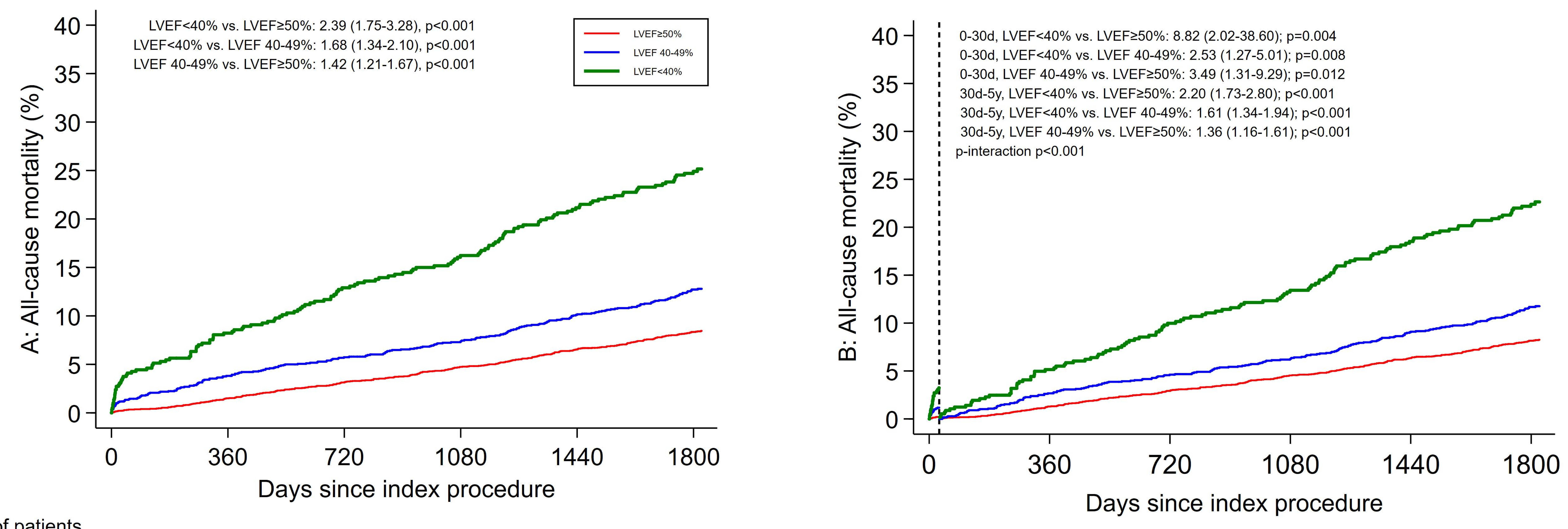

$\mathrm{Nr}$ of patients

$\begin{array}{rcccccc}\text { LVEF } \geq 50 \% & 3816 & 3722 & 3632 & 3541 & 3465 & 2992 \\ \mathrm{LEF} 40-49 \% & 1793 & 1707 & 1659 & 1611 & 1561 & 1305 \\ \mathrm{LVEF}<40 \% & 589 & 532 & 502 & 477 & 446 & 359\end{array}$



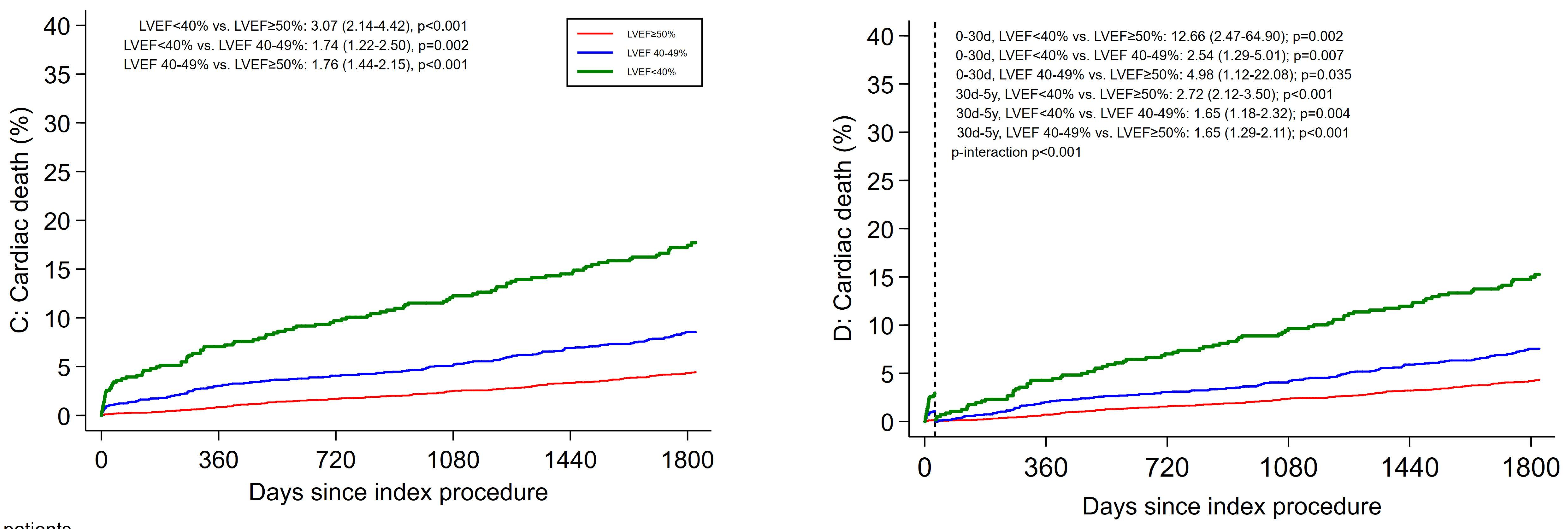

$\mathrm{Nr}$ of patients

LVEF $\geq 50 \% \quad 3816$ 

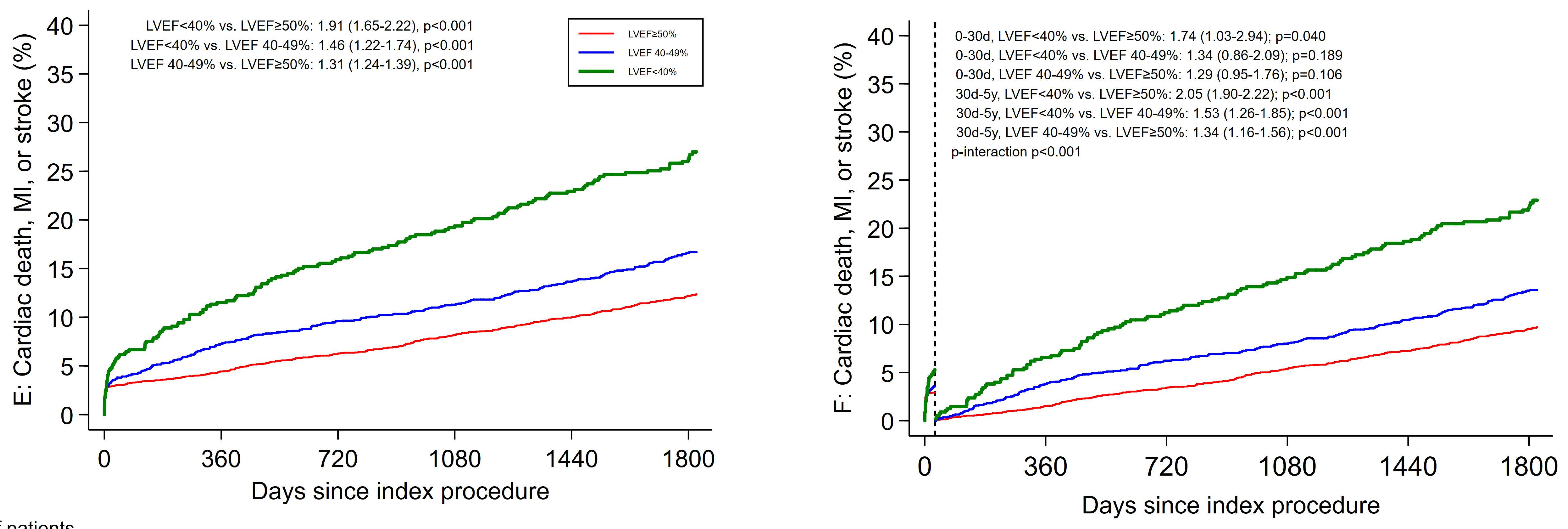

$\mathrm{Nr}$ of patients

LVEF $\geq 50 \% \quad 3816$

LVEF 40-49\% 1793 

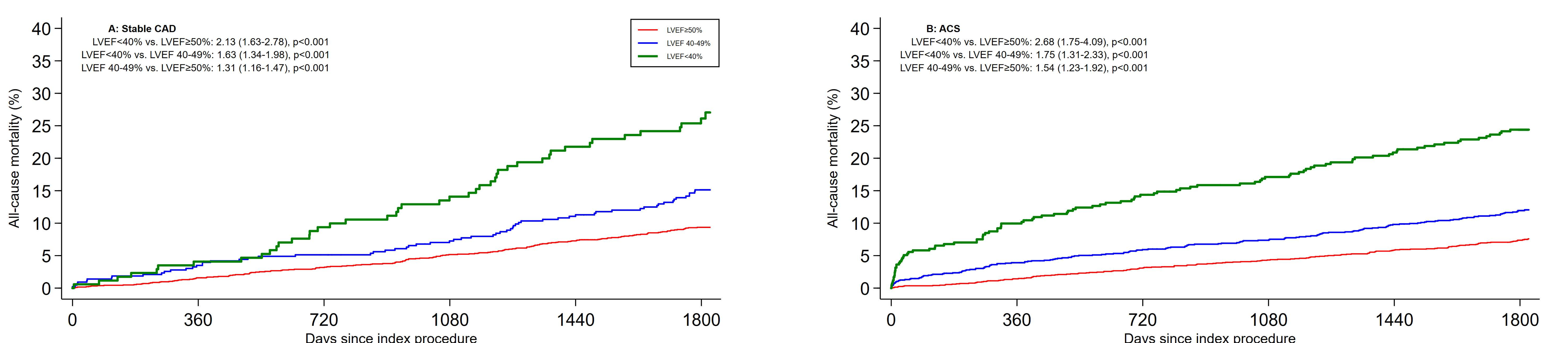

$\mathrm{Nr}$ of patients

$\begin{array}{rr}\text { LVEF } 250 \% & 1840 \\ \text { LVEF } 40-49 \% & 429\end{array}$

Dys since index procedure

$\mathrm{Nr}$ of patients

$\begin{array}{llll} & & & \\ 1756 & 1711 & 1669 & 1418 \\ 405 & 391 & 375 & 302 \\ 154 & 146 & 131 & 98\end{array}$

LVEF $\geq 50 \%$
LVEF $40-49 \%$

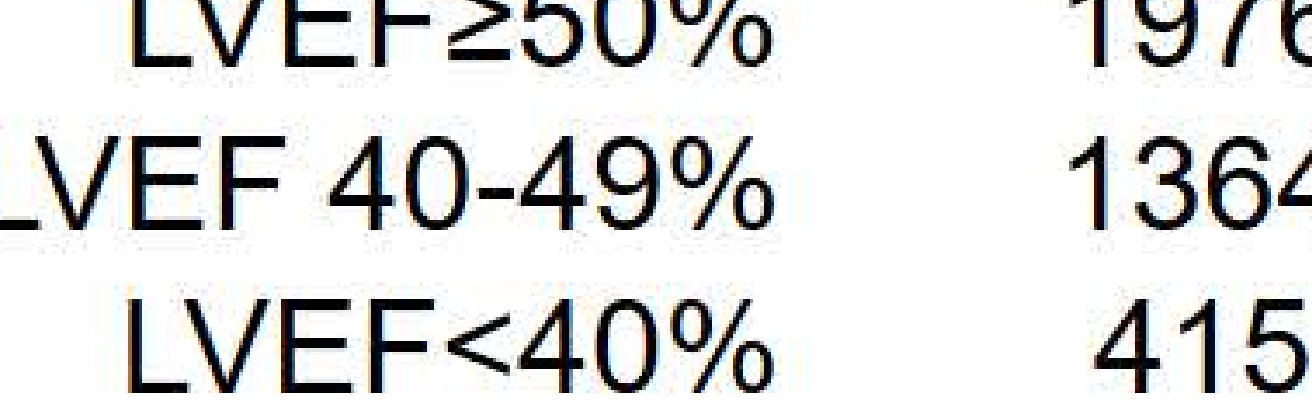

1922
1293
368

1876
1254
348

1830
1220
331

1796
11186
315

1574
1003
261 

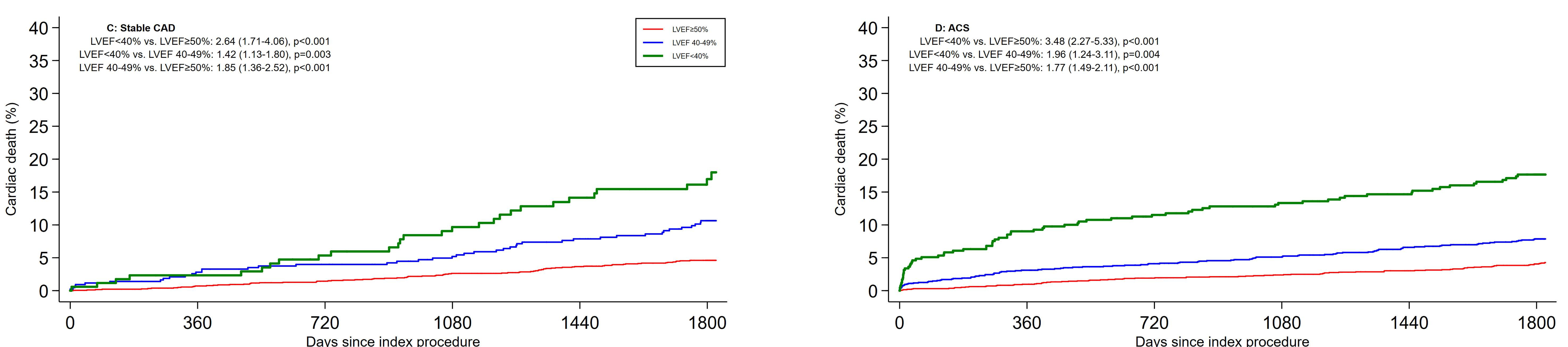

$\mathrm{Nr}$ of patients

$\begin{array}{rr}\text { LVEF } 250 \% & 1840 \\ \text { LVEF } 40-49 \% & 429\end{array}$

1800
414
164

1711
391
146

1669
375
131

1418
302
98

$\mathrm{Nr}$ of patients

$\begin{array}{rr}\text { LVEF } 250 \% & 1976 \\ \text { LVEF } 40-49 \% & 1364 \\ \text { LVEF }<40 \% & 415\end{array}$

1922
1293
368

1876
1254
348

1830
1220
331

1796
1186
315

1574
1003
261 

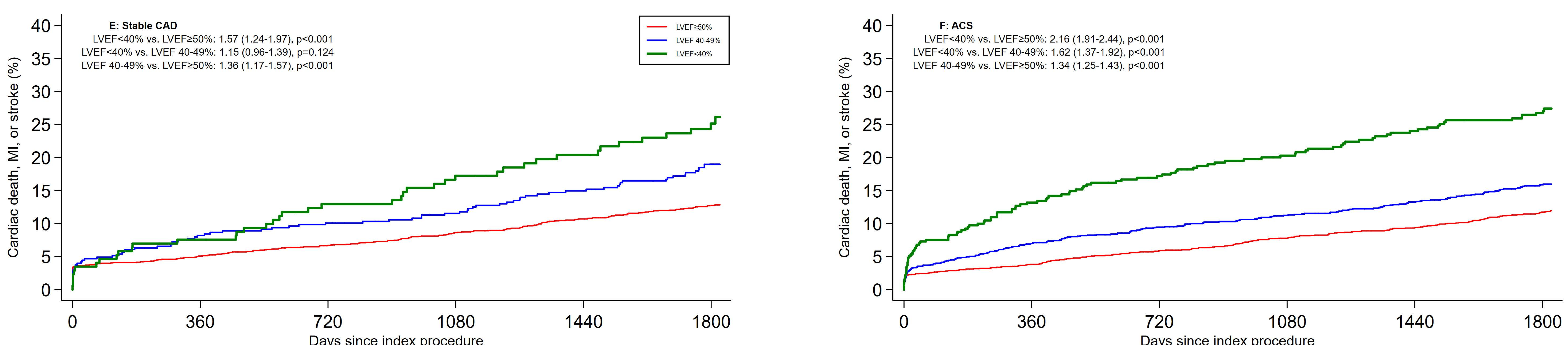

$\mathrm{Nr}$ of patients

$\begin{array}{rr}\text { LVEF } 250 \% & 1840 \\ \text { LVEF } 40-49 \% & 429\end{array}$

ays since index procedure

$1302 \quad$ Nr of patients

$\begin{array}{cccc}1663 & 1606 & 1550 & 1302 \\ 379 & 364 & 345 & 275 \\ 142 & 135 & 123 & 91\end{array}$

$\begin{array}{rr}\text { LVEF } 250 \% & 1976 \\ \text { LVEF 40-49\% } & 1364 \\ \text { LVEF }<40 \% & 415\end{array}$

1866
1244
351

1800
1189
325

1728
1146
304

1679
1106
281

1456
923
230 

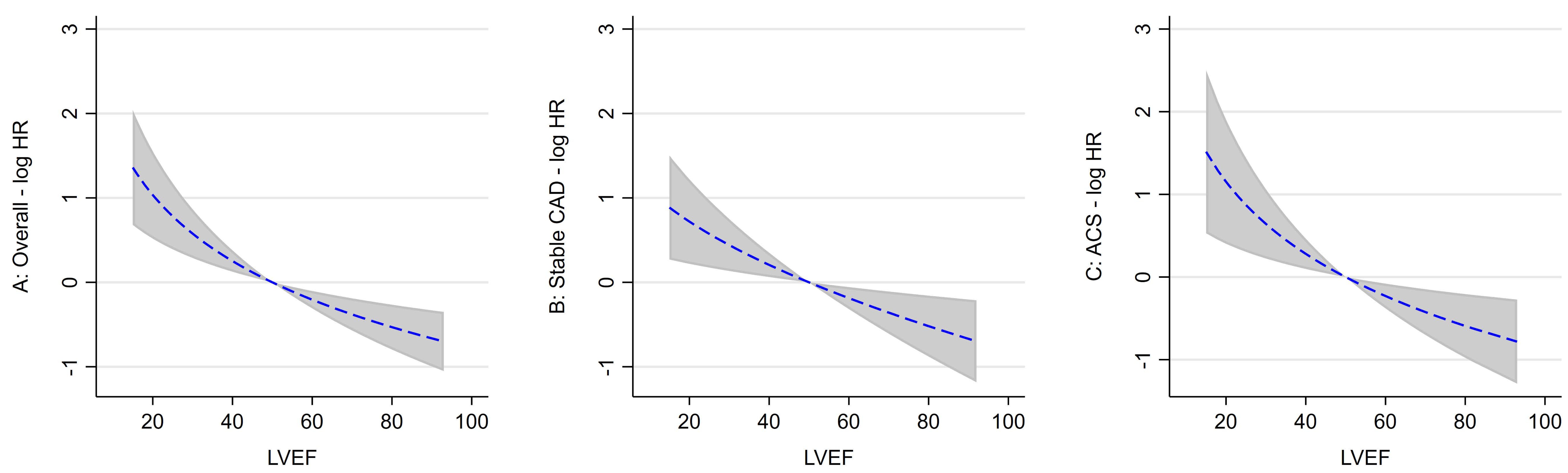